Gönderilme Tarihi: 8 Ağustos 2016

Kabul Tarihi: 29 Kasım 2016

\title{
YAVAŞ ŞEHİR (CITTASLOW) TÜRKİYE AĞI'NA ÜYE OLAN ŞEHİRLERİN İNTERNET SİTELERİNDE YAVAŞ ŞEHİR TEMASININ GÖRÜNÜRLÜĞÜ ÜZERİNE BİR ARAŞTIRMA
}

\author{
Ömer ÇOBAN*, Serhat HARMAN**
}

Öz

Yavaş şehir (Cittaslow) hareketi, İtalya kaynaklı bir hareket olup, şehirlerin yerel, eşsiz ve tarihi kaynaklarına öncelik veren planlama ve kentsel tasarım yoluyla, küreselleşme ve şirket-merkezli gelişime topluca karşı çıkan şehirlerin oluşturduğu küresel bir ağ olarak tanımlanabilir. Yavaş şehir ağına üye olan şehirlerde, yavaş şehir temasının önemli bir farklılaştırma aracı olarak kullanılma potansiyeli bulunmaktadır. Bu amaçla çalışmada, Yavaş Şehir Türkiye Ağı́na üye olan şehirlerin internet sitelerindeki yavaş şehir temasının görünürlüğü, doküman analizi yöntemi ile incelenmiş ve toplanan veriler içerik analizine tabi tutulmuştur. İnternet sitelerine dayalı olarak yapılan içerik analizi, yavaş şehir ağına üye olan şehirlerin görünürlüğü konusunda sıkıntılar olduğunu işaret etmektedir. Çalışma, Türkiye'deki yavaş şehirlere yönelik öneriler ile son bulmaktadır.

Anahtar Sözcükler: Yavaş Şehir, Yavaş Yemek, İnternet, Tema, Görünürlük, Türkiye

\section{A RESEARCH ON VISIBILITY OF CITTASLOW THEME IN WEB SITES OF CITTASLOWS IN TURKEY}

\begin{abstract}
Cittaslow movement can be defined as an Italian-originated organization of small cities which collectively resist globalization and mainstream business-oriented extended through giving priority to sustainable planning and urban design of local unique historical resources. Visibility of cittaslow theme has a potential to be an important differentiation tool in cittaslows. In this study, data on visibility of cittaslow theme in cittaslows in Turkey was collected by document analysis and analysed via content analysis. Findings of content analysis indicate that there are some problems about visibility of cittaslow theme. The study ends with some suggestions to cittaslows in Turkey.
\end{abstract}

Keywords: Cittaslow, Slow Food, Internet, Theme, Visibility, Turkey

\footnotetext{
* Batman Üniversitesi Turizm İşletmeciliği ve Otelcilik Yüksekokulu, E-Posta: ocoban@yahoo.com

** Batman Üniversitesi Turizm İşletmeciliği ve Otelcilik Yüksekokulu, E-Posta: harmanserhat@hotmail.com
} 


\section{GİRİ̧̧}

Yavaş şehir hareketi, toplumun ve ziyaretçilerin yaşam kalitesini yükseltmeyi hedefleyen ve yavaş yemek (Slow Food) felsefesini, küçük ölçekli şehir veya kasabaların tasarımı ve planlamasında kullanmayı amaçlayan küresel bir ağdır (Yurtseven, Kaya ve Harman, 2010). Görkem ve Öztürk (2014) ise yavaş şehir hareketini, yavaş yemek hareketinden ortaya çıkmış, şehirlerin ve şehirlerdeki yerel halkın unutulmaya yüz tutmuş yerel yaşam tarzlarının korunmasına küresel düzeyde standartlar getirilmesi için kurulmuş bir sivil toplum örgütü olarak tanımlamaktadır. Yavaş şehir hareketi kapsamında, belirli bir şehrin kendine özgü kaynaklarının kullanımı ve geliştirilmesi hedeflendiğinden, yavaş şehir hareketi artık turizm açısından, destinasyonların geliştirilmesinin de önemli bir aracı haline gelmiştir (Nilsson, Svärd, Widarsson ve Wirell, 2011).

Çalışmada, Yavaş Şehir Türkiye Ağı́na üye olan şehirlerin internet sitelerinde, yavaş şehir temasının görünürlüğü incelenmiştir. Kurum ve şehir kimliğinin en önemli bileşenlerinden birisinin görsel ögeler olması bu incelemeye gerek duyulmasının altında yatan temel nedenlerden biridir. Bunun yanı sıra, bir destinasyonu ziyaret edecek turistler, seyahatleri öncesi gidecekleri destinasyon hakkında farklı kaynaklardan bilgi arayışına girmektedirler. Bu süreçte bilgi teknolojilerinde yaşanan gelişmelerle birlikte, internet ve sosyal medya turistlerin en çok tercih ettikleri bilgi kaynaklarından biri haline gelmiştir (Chung ve Koo, 2015). Buradan hareketle, yavaş şehir ağına üye olan belediyelerin internet sayfaları ve sosyal medya hesaplarının, o şehri ziyaret etmeyi planlayan turistlerce ziyaret öncesinde kontrol edilmesinin olası olduğu söylenebilir. Bu nedenle, yavaş şehir ağına üye olan belediyelerin internet sayfaları ve sosyal medya hesaplarında yavaş şehir temasının görünürlüğü önem arz etmektedir. Alanyazın incelendiğinde yavaş şehirlerin internet siteleri üzerinden yavaş şehir temasının görünürlüğüne ilişkin gerçekleştirilen bir çalışmaya rastlanmamıştır. Bu amaçla çalışmada, Yavaş Şehir Türkiye Ağı'na üye olan şehirlerin internet siteleri ve sosyal medya hesapları üzerinden yavaş şehir temasının görünürlüğü araştırılmıştır. Çalışmanın, görünürlük konusunda ağa üye olan yavaş şehirler için farkındalık yaratması ve belediyeleri, görünürlük konusundaki eksiklikleri gidermeye sevk etmesi beklenmektedir. Aynı zamanda çalışmanın, az sayıda ampirik (görgül) çalışma bulunan yavaş şehir alanyazınına katkı sağlaması beklenmektedir. 


\section{Ömer Çoban ve Serhat Harman}

Çalışmada, verilerin ikincil kaynaklardan (internet sitelerinden) doküman analizi tekniği ile toplandığı ve içerik analizi ile analiz edildiği nitel bir araştırma gerçekleştirilmiştir. Çalışmada öncelikle, yavaş şehir hareketi ve yavaş şehir kriterlerine ve yavaş şehir çalışmalarına ilişkin bir yazın taramasına yer verilmiştir. Bunu araştırmanın amacı, veri toplama tekniğine ve verilerin analizine ilişkin açıklamaların sunulması takip etmektedir. Çalışma sonunda, yavaş şehir yöneticilerine, internet sayfalarında yavaş şehir temasının kullanıma ilişkin çeşitli öneriler getirilmiştir.

\section{ALANYAZIN TARAMASI}

Küreselleşme, ulaşabildiği yerlerde yerellik kavramını ortadan kaldıran köklü bir değişime neden olmaktadır (Coşar, 2013). Küresel dünyanın en önemli aktörleri arasında yer alan işletmeler açısından, zaman önemli bir maliyet unsuru olarak görülmektedir (Öztürk, 2012a). Küreselleşme ve kapitalizmin zorunlu kıldığı "hız", hayatın her alanında ortaya çıkmaktadır (Çoban, 2010; Şahin ve Kutlu, 2014). Bu nedenle "hı" ve "hızlı olmak" küresel dünyanın mottosu haline gelmiştir. Yavaş yaşam anlayışı, küreselleşme sürecine bir tepki olarak ortaya çıkmıştır (Güven, 2011). Küreselleşme ile tüm dünyaya yayılan ve hayatın her alanında geri dönüşü ve dönüşümü olmayan çapta bir tüketim; hızlı yaşam ortamına/alışkanlığına karşı, sürdürülebilirliğin gerekliliğine inanan kişi ve toplumlar tarafından yavaş yaşam hareketleri ortaya atılmıştır (Özkan, 2011). Yavaş yaşam hareketi, 1986 yılında İtalya'nın Roma kentinde McDonalds açılışının Carlo Petrini önderliğindeki grup tarafından, "meydanın estetiğinin bozulacağını" ve "yemek yemenin abur cuburla doymak olmadığını" çarpıcı biçimde anlatabilmek amacıyla gerçekleştirdikleri eyleme dayanmaktadır (Güven, 2011; Özgenç, 2012; Yurtseven vd., 2010;. Bu eylem, yavaş yemek hareketinin de temelini oluşturmuştur. Bu akım, yeme-içme kültürünün gelişmesine, tutundurulmasına önem veren küresel bir ağdır (Yurtseven vd., 2010).

Yavaş şehir, İtalya kaynaklı olup, her bir şehrin yerel eşsiz ve tarihi kaynaklarına öncelik veren planlama ve kentsel tasarım yoluyla, küreselleşme ve şirket-merkezli gelişime topluca karşı çıkıldığı, şehirlerin oluşturduğu küresel ağdır (Semmens ve Freeman, 2012). Yavaş şehir hareketi 1999 yllında Greve in Chianti'nin eski belediye başkanı Paolo Saturnini'nin vizyonu doğrultusunda ortaya çıkmıştır. Paolo Saturnini yaşam kalitesini yükseltmek amacıyla şehirlerin öz değerlendirmelerini ve alternatif bir kalkınma yaklaşımı sunmaları fikrini ulusal boyuta taşımışır. Saturnini'nin fikirleri, kısa sürede Bra (Francesco Guida), Orvieto (Stefano 
Yavaş Şehir (Cittaslow) Türkiye Ağı'na Üye Olan Şehirlerin İnternet Sitelerinde Yavaş Şehir Temasının Görünürlüğü Üzerine Bir Araştırma

Cimicchi) ve Positano (Domenico Marrone) belediye başkanları ve yavaş yemek hareketi başkanı Carlo Petrini tarafından kabul edilmiştir (Cittaslow, 2015).

Cittaslow, İtalyanca Citta (Şehir) ve İngilizce Slow (Yavaş) kelimelerinin birleşmesinden meydana gelmektedir (Çerçi, 2013; Karakurt Tosun, 2013; Yalçın ve Yalçın, 2013). Cittaslow kavramına yerli yazında farklı şekillerde yer verilmektedir. Bu kullanımlar arasında "yavaş şehir" (Coşar, 2013; Çerçi, 2013; Doğutürk, 2010; Erten, 2009; Göçkan, 2012; Günerhan, Erdem ve Günerhan, 2010; Keskin, 2010; Onaran, 2013; Özgenç, 2012; Özkan, 2011; Öztürk, 2012b; Sezgin ve Ünüvar, 2011; Toplu, 2012; Yurtseven, vd., 2010), "yavaş kent" (Polat, 2011; Öztürk, 2012a), "sakin şehir" (Baykan, 2014; Ekincek, 2014; Mutdoğan, 2010; Sırım, 2012) yer almaktadır. Yavaş şehir kavramının kullanımı diğer kullanımlara göre daha yaygındır. Bu nedenle çalışmada yavaş şehir kavramı kullanılmıştır. Yavaş şehir kavramının kökenleri yavaş yemek hareketine kadar uzanmaktadır (Baykan, 2014; Özgenç, 2012). Günümüzde yavaş hareketinin alanı genişlemiş; yaşam, seyahat, eğitim, okuma, para ve birçok diğer alanda tüketim konusunda ortak bir "yavaşı|k" felsefesi hakim hale gelmiştir (Bahtiyar Karadeniz, 2014). İki hareketin amaçları birbirinden farklı olsa da her iki hareket birbirini tamamlayıcı niteliklere sahiptir (Coşar, 2013). Miele (2008) ise yavaş şehir hareketinin yavaş yemek felsefesini şehirlerin tasarım ve planlamasında kullanmayı amaçlayan uluslararası bir ağ olduğunu vurgulamaktadır. Bu nedenle, günümüzde 30 ülkede 222 üyeye yayılan yavaş şehir hareketinin amacı yavaş yemek felsefesini kentsel boyuta taşımaktır (Cittaslow, 2016). Görkem ve Öztürk'e göre (2014) yavaş şehir hareketi, yavaş hareketinin geleneksel ve doğal yeme içme alışkanlarını korumayı, yerel yiyecek içeceklerin kullanımını yaygınlaştırmayı, hızlı yemek akımının dezavantajlarına dikkat çekmeyi ve doğal kaynakların sürdürülebilir kullanımı felsefesini kentsel bağlama taşımayı amaçlamaktadır.

Türkiye'de yavaş şehir hareketi, 28 Kasım 2009 tarihinde Seferihisar'ın bu ağa katılmasıyla resmi olarak başlamışıır (Sünnetçioğlu, Can ve Durlu-Özkaya, 2012). Yaklaşık yedi yıllık süreçte Yavaş Şehir Türkiye Ağı'na üye olan şehir sayısı on bire çıkmıştır (Cittaslow Türkiye, 2016). Bu şehirler arasında Seferihisar (İzmir), Akyaka (Muğla), Gökçeada (Çanakkale), Taraklı (Sakarya), Yenipazar (Aydın), Yalvaç (Isparta), Perşembe (Ordu), Vize (Kırklareli), Halfeti (Şanlıurfa), Şavşat (Artvin) ve Uzundere (Erzurum) yer almaktadır (Cittaslow Türkiye, 2016). Uluslararası Yavaş Şehir Birliği'ne başvuru işlemlerini, Yavaş Şehir Türkiye 


\section{Ömer Çoban ve Serhat Harman}

Ağı sekretaryası ve koordinatörlüğü sürdürmektedir. Bir şehrin bu harekete üye olabilmesi için nüfusunun 50.000 'den az olması ve şehir yönetiminin yavaş şehir felsefesini benimsemiş olması gerekmektedir. Şehirlerin ağa üye olabilmesi için altı aşamalı bir süreçten geçmesi gerekmektedir (Cittaslow Türkiye, 2015c). Bu aşamalar; (1) başvuru mektubunun hazırlanması, (2) bilgilendirme toplantısı ve değerlendirme ziyareti, (3) başvuru dosyasının hazırlanması ve teslimi, (4) başvuru dosyasının değerlendirilmesi, (5) başvuru dosyasının genel merkeze gönderilmesi ve (6) üyelik ilanından oluşmaktadır.

28 madde ve 5 ek belgeden oluşan "Uluslararası Yavaş Şehir Tüzüğü", birliğin kuruluşu, organları, birliğe üye olabilmek için kriterler, üyelerin sorumlulukları, logo ve diğer tanıtım materyallerinin kullanımı, fonların kullanımı dahil olmak üzere birçok hususu bünyesinde barındırmaktadır (Keskin, 2012). Birliğin kuruluş maddesinde; "Birlik, modern ve tarihi binalardan oluşan bir taç taşıyan turuncu renkli bir salyangozu resmeden kendi logosunu kullanacaktır. Logonun ayrılmaz bir parçası ise, salyangoz figürünün altında yer alan "Yaşam kalitesine önem verilen şehirlerin uluslararası ağı" sözü olacaktır" denilmektedir (Çerçi, 2013; Öztürk, 2012a). Şekil 1'de birlik logosuna yer verilmiştir.

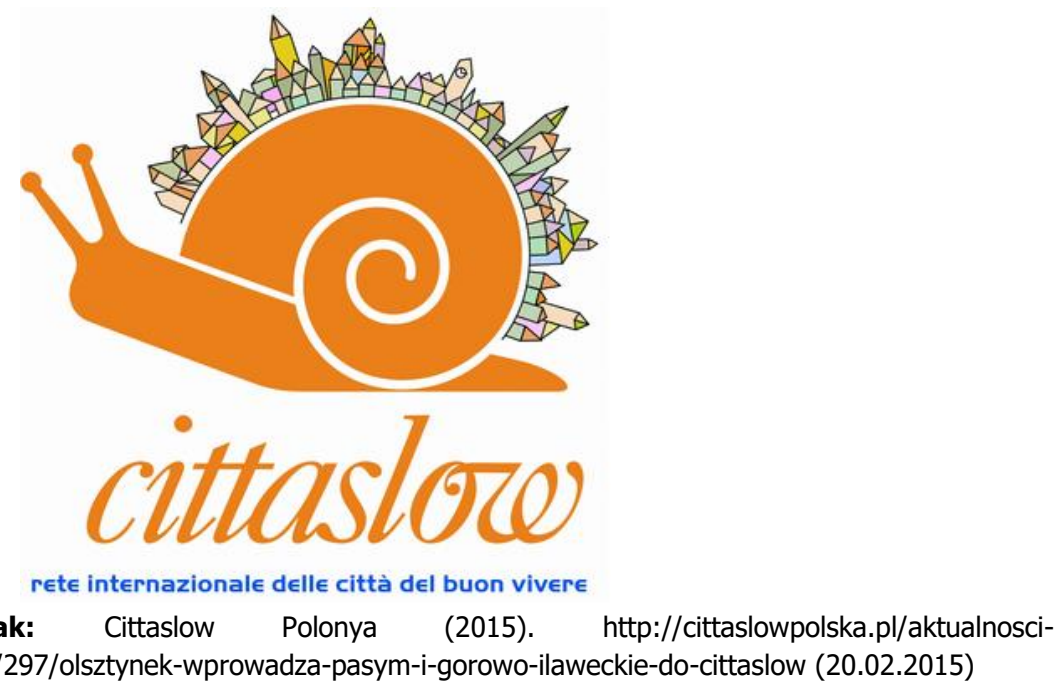
czytaj/297/olsztynek-wprowadza-pasym-i-gorowo-ilaweckie-do-cittaslow (20.02.2015)

\section{Şekil 1: Yavaş Şehir Logosu}

Uluslararası Yavaş Şehirler Birliği'nin logo olarak salyangozu seçmesinin temel nedeni, salyangozun yavaşlık ve dinlenmeyi temsil etmesidir. Salyangoz, yavaş bir şekilde hareket etmekte ve evi olan kabuğunu gittiği her yere götürmektedir. Bu yavaşlık, düşünmeyi ve ağırbaşlılığı akla getirmektedir (Keskin, 2010). Ağa kabul edilen şehirlere 
Yavaş Şehir (Cittaslow) Türkiye Ağı'na Üye Olan Şehirlerin İnternet Sitelerinde Yavaş Şehir Temasının Görünürlüğü Üzerine Bir Araştırma

"Salyangoz Bayrağı" dalgalandırma hakkı verilmektedir. Salyangoz bayrağı, yavaş şehir hareketini simgeleyen bir kalite işaretidir (Sırım, 2012).

Alanyazın incelendiğinde çalışmaların birçoğunun ikincil kaynak taramalarına dayandırılan ve yavaş şehir hareketini irdelemeye dönük çalışmalardan oluştuğu görülmektedir. Yavaş şehir hareketini küreselleşme, yerelleşme ve yerel kültür üzerinden ele alan çalışmaların (Coşar, 2013; Grzelak-Kostulsk, Hołowiecka ve Kwiatkowski, 2011; Jarvis, 2015; Mayer ve Knox, 2006; Pecsek, 2016; Servon ve Pink, 2015; Steele, 2012) sayısının fazlalığı göze çarpmaktadır. Bunun nedeni yavaş şehir hareketinin bir yerelleşme hareketi olmasına rağmen, kısa sürede uluslararası bir yapıya kavuşması olarak açıklanabilir. Bunun yanı sıra yazında yavaş şehir hareketini, sürdürülebilirlik, sürdürülebilir turizm, sürdürülebilir şehir bağlamında ele alan birçok çalışma (Bahtiyar Karadeniz, 2014; Baldemir, Kaya ve Kaşmer Şahin, 2013; Ekincek, 2014; Jung, Ineson ve Miller 2014; Keskin, 2010; Mayer ve Knox, 2006; Semmens ve Freeman, 2012; Sezgin ve Ünüvar, 2011; Şahin ve Kutlu, 2014; Yalçın ve Yalçın, 2013) bulunmaktadır. Yavaş şehir ağına üye olmaya yönelik kriterler incelendiğinde, kriterlerin önemli bir kısmının sürdürülebilirlik felsefesine uygun olması, bu çalışmaların sayısının fazla olmasının temel nedeni olarak gösterilebilir. Diğer taraftan yavaş şehir ağına üye olan yerlerin planlı bir şehir tasarımına sahip olması gerektiğinden; doğal ve kültürel yapı, kentleşme, şehir planlaması, mimari, çevre ve enerji konularında da (Doğutürk, 2010; Günerhan, Erdem ve Günerhan, 2010; Erten, 2009; Göçkan, 2012; Onaran, 2013; Özgenç, 2012; Öztürk, 2012a; Öztürk, 2012b; Polat, 2011) önemli sayıda çalışma üretildiği görülmektedir. Yavaş şehir hareketinin temelinde yavaş felsefesi ve yavaş yemek felsefesinin yatmasından dolayı bu kavramlar arası ilişkiyi irdeleyen çalışmalara da (Broadway, 2015; Eşitti ve Demir Harputluoğlu, 2015; Görkem ve Öztürk, 2014; Nilsson, Svärd, Widarsson ve Wirell, 2011) alanyazın taramasında rastlanmıştır. Yavaş şehir ağına üye olmak, ağa üye olan şehirlerin pazarlanabilmesini kolaylaştırmakta ve bu şehirlere, turistlerin diğer destinasyonlardan daha farklı motivasyonlarla gelmesini sağlamaktadır. Alanyazında yavaş şehir ve destinasyon pazarlaması, destinasyon markalaması, turist davranışı ve yavaş turist bağlamında ele alınan çalışmalarda (Coşar, 2013; Cosar ve Kozak, 2014; Çerçi, 2013; Georgica, 2015; Karabag, Yucel ve Inal, 2012; Meng ve Choi, 2016; Sezgin ve Ünüvar, 2011; Yurtseven ve Kaya, 2011) bu konuların detaylı bir şekilde incelendiği görülmektedir. Bu 


\section{Ömer Çoban ve Serhat Harman}

çalışmalardan çok azı ampirik nitelik taşımakla birlikte, çalışmalarda hem nicel (Cosar ve Kozak, 2014; Georgica, 2015; Meng ve Choi, 2016; Pecsek, 2016; Yurtseven ve Kaya, 2011) hem de nitel (Baldemir, Kaya ve Kaşmer Şahin, 2013; Eşitti ve Demir Harputluoğlu, 2015; Jung, Ineson ve Miller 2014) yöntemler kullanılmıştır.

Yavaş şehir hareketinin ortaya çıkışı her ne kadar uzun yıllar öncesine dayansa da, konu üzerine az sayıda ve ampirik olmayan çalışmaların ağırlıkta olduğu söylenebilir. Buradan hareketle; yavaş şehirlerin yönetimi, tanıtımı ve pazarlanması ve bu şehirlere gelen turistlerin deneyimleri başta olmak üzere ampirik çalışmaların artması, yavaş şehir kavramının bütüncül bir bakış açısıyla anlaşılmasına olanak sağlayacağı aşikardır. Yavaş şehirlere seyahat eden turistlerin gittikleri şehir hakkında bilgi edindikleri kaynaklar içerisinde internet ve sosyal medya kaynakları önemli bir yer tutmaktadır (Georgica, 2015; Yurtseven ve Kaya, 2011). Yavaş şehir ağının uluslararası belediyeler birliği olduğu düşünüldüğünde, belediyelerin internet sitelerinin ve belediyeler tarafından yönetilen sosyal medya hesaplarının turistler tarafından öncelikli olarak kontrol edilmesi muhtemeldir. Diğer taraftan ağa üye olan belediyeler, yavaş şehir üyeliğini şehrin markalaşması ve tanıtılması amacıyla kullanabilmektedir. Bu da şehri ziyaret edenlerin de, şehre ait internet sitelerini ve sosyal medya hesaplarını ziyaret edenlerin de yavaş şehir ile ilgili bilgilere birincil elden ve kolayca ulaşabilmesi gerekliliğini ortaya çıkarmaktadır. Bu nedenle alanyazında böyle bir çalışmaya rastlanmadığından, yavaş şehir ağına üye olan belediyelerin internet siteleri üzerinden yavaş şehir temasının görünürlüğünü araştıran bir araştırma gerçekleştirilmiştir. Çalışmanın bu yönü ile alanyazına da katkı sağladığı söylenebilir.

\section{ARAŞTIRMANIN YÖNTEMİ}

\section{Araştırmanın Amacı}

Günümüzde şehirlerin artık birbirlerine benzer hale geldiklerini söylemek olanaklıdır. Ziyaretçiler tarafından tercih edilen bir yer olmak, kendilerini diğer şehirlerden farklılaştırmak ve kültürel/tarihsel kaynaklarının devamlıı̆ını sağlamak isteyen şehirler için yavaş şehir ağı önemli fırsatlar sunabilmektedir. Nitekim yavaş şehir hareketine katıldıktan sonra, şehrin turistlerce tercih edilme oranı artmaktadır (Sezgin ve Ünüvar, 2011). Dolayısıyla yavaş şehir ağına üye olan şehirler için "yavaş" teması önemli bir farklılaştırma aracı olmaktadır. 
Yavaş Şehir (Cittaslow) Türkiye Ağı'na Üye Olan Şehirlerin İnternet Sitelerinde Yavaş Şehir Temasının Görünürlüğü Üzerine Bir Araştırma

Ziyaretçiler, bir turistik destinasyonu tatil için seçerlerken birçok kaynaktan bilgi toplamaktadırlar. Bu kaynakların başında internet ve sosyal medya kaynakları gelmektedir (Chung ve Koo, 2015; Georgica, 2015; Jacobsen ve Munar 2012; Yurtseven ve Kaya, 2011). Yavaş şehir ağına üyeliğin belediyeler üzerinden gerçekleştiği düşünüldüğünde yerel yönetimlerin kontrolünde olan internet sitelerinin ve sosyal medya hesaplarının turistler tarafından öncelikli olarak kontrol edilmesi olasıdır. Ayrıca, belediyelerin kendilerini diğer şehirlerden farklılaştıran yavaş şehir temasına, haberlere ve etkinliklere internet sitelerinde yer vermelerinin şehirlerinin tanıtımına katkı sunacağı aşikardır.

Yavaş şehir ağına üye olan şehirler, üyelik kriterlerine göre "Cittaslow kampanyaların desteklemek" ve "Cittaslow logosuna internet sayfasında ve antetli kağıt üzerinde yer vermek" ile yükümlü tutulmuşlardır (Cittaslow Türkiye, 2015b). Bu bağlamda çalışmada Yavaş Şehir Türkiye Ağı́na üye olan şehirlerin kurumsal internet sitelerinde, yavaş şehir temasının görünürlüğünün incelenmesi amaçlanmıştır. Böylelikle, Yavaş Şehir Türkiye Ağı́na üye olan şehirlerin kurumsal internet sitelerinde yavaş şehir temasını görünürlüğü ve farkındalık yaratma konusundaki eksiklikler var ise, bu eksikliklerin giderilmesine yönelik, şehirlere çeşitli önerilerin getirilmesi hedeflenmiştir.

\section{Veri Toplama Tekniği ve Analizi}

Yavaş Şehir Türkiye Ağı'na üye olan şehirlerde yavaş şehir temasının görünürlüğünün irdelendiği bu çalışma, nitel araştırma olarak tasarlanmışıı. Nitel araştırma, nitel veri toplama teknikleri olan gözlem, görüşme ve doküman analizi kullanılarak, algıların ve olayların doğal ortamında gerçekçi ve bütüncül olarak ele alınmasını sağlayan araştırma desenlerinin bütününe verilen addır (Yıldıım ve Şimşek, 2008). Bu çalışmada yavaş şehir temasının, Yavaş Şehir Türkiye Ağı'na üye olan şehirlerdeki görünürlüğü incelenirken, doküman analizi tekniğine başvurulmuştur. Doküman analizi, araştırılması hedeflenen olay ve olgular hakkında bilgi veren her türlü basıll, görsel, elektronik kaynağın incelenmesidir (Yıldırım ve Şimşek, 2008). Doküman analizine konu olan kaynaklar; arşiv verileri ve tarihsel veriler (Baş ve Akturan, 2008) olabileceği gibi, film, video ve fotoğraflar da (Yıldıım ve Şimşek, 2008) olabilmektedir. Baş ve Akturan (2008) internet kaynaklarının da doküman analizleri kapsamında başvurulan kaynaklar arasında olduğunu belirtmektedirler. Çalışmada doküman analizine konu olan dokümanlar, Yavaş Şehir Türkiye Ağı́na üye olan şehirlerin kurumsal internet 


\section{Ömer Çoban ve Serhat Harman}

siteleridir. Yavaş şehir uluslararası belediyeler birliğidir (Cittaslow Türkiye, 2015a). Dolayısıyla ağa üyelikler belediyeler üzerinden gerçekleştirilmektedir. Bu nedenle bahsi geçen siteler belediyelerin sahip olduğu "bel.tr" uzantılı sitelerdir.

Nitel verilerin toplanmasının ardından, toplanan verilerin analiz edilmesi gerekmektedir. Nitel verilerin analizinde kullanılan tekniklerden biri, içerik analizidir (Yıldırım ve Şimşek, 2008). İçerik analizi; çeşitli dokümanların içeriğini, temel unsurlarını sınıflandırmak ve yorumlamak maksadıyla metodik, sistematik, tarafsı ve elverişli ise nicel olarak incelenmesine imkân veren bir tekniktir (Bilgin, 2006). Çalışmada, Yavaş Şehir Türkiye Ağı'na üye olan on bir şehrin kurumsal internet siteleri 2030 Ekim 2016 tarihleri arasında ziyaret edilmiş ve bu şehirlerin internet siteleri yavaş şehir temasının görünürlüğü bakımından incelenmiştir. Görünürlüğe ilişkin kategoriler belirlenirken kontrol ve denetim açısından geçerliğin sağlanabilmesi için uzman teyidine başvurulmuştur. Uzman teyidi, nitel araştırmalarda geçerliği sağlamak için çeşitleme ve katııııı teyidi ile birlikte kullanılacak araçlardan birisidir (Yıldııı ve Şimşek, 2008). Bu bağlamda, yavaş şehirler üzerine çalışma yapan iki uzmanın görüşleri alınarak görünürlüğe ilişkin kategoriler belirlenmiştir. Bahsi geçen iki araştırmacıdan ilkinin yavaş şehirler üzerine biri kitap olmak üzere çeşitli çalışmaları, ikinci araştırmacının konu üzerinde çalışmalarla birlikte, "Cittaslow International" bilim kurulu üyeliği bulunmaktadır. Belirlenen kategoriler aşağıdaki başlıklardan oluşmaktadır:

- Ana sayfada yavaş şehir logosuna yer verilmesi,

- Diğer sayfalarda yavaş şehir logosuna yer verilmesi,

- Yavaş şehir ile ilgili haberlere yer verilmesi,

- Yavaş şehir hakkında bilgi/link verilmesi,

- Sosyal medya üzerinden yavaş şehir hakkında paylaşım yapılması,

- Bağımsız bir yavaş şehir sitesi,

- E-gazete/e-dergi veya $360^{\circ}$ sanal turda yavaş şehir logosuna ve haberlerine yer verilmesi.

Kirk ve Miller (1986) nitel araştırmalarda iç ve dış güvenirliğin sağlanabilmesi için çeşitli birden fazla kodlayıcının ayrı ayrı kodlamalar yapması gerektiğini ve farklı zamanlarda yapılan kodlamalarda benzer sonuçlara ulaşılması gerektiğini vurgulamaktadır. Bu maksatla çalışmada, iç güvenirliğin sağlanabilmesi için araştırmacılar içerik analizine konu olan verileri ayrı ayrı kodlamışlardır. Diğer taraftan, verilerin toplandığı 20-30 Ekim 2016 tarihleri arasında internet siteleri birden fazla kez ziyaret edilerek dış güvenirliğin sağlanması amaçlanmıştır. 
Yavaş Şehir (Cittaslow) Türkiye Ağı'na Üye Olan Şehirlerin İnternet Sitelerinde Yavaş Şehir Temasının Görünürlüğü Üzerine Bir Araştırma

\section{Araştırma Bulguları}

Yavaş Şehir Türkiye Ağı'na 2016 yılı Ekim ayı itibariyle 11 şehir üye olarak bulunmaktadır. Yavaş Şehir Türkiye Ağı'na üye olan şehirlerin üyelik tarihlerine Tablo 1'de yer verilmiştir. Buna göre İzmir'in Seferihisar ilçesi Türkiye'den yavaş şehir hareketine ilk üye olan şehir olarak ağın başkenti olmuştur. Ardından 2011 yılında Akyaka, Gökçeada, Taraklı ve Yenipazar harekete katılmışlardır. 2012 yılında Yalvaç, Perşembe, Vize'nin üye olmasıyla Yavaş Şehir Türkiye Ağı'na dahil olan şehir sayısı sekize çıkmıştır. 2013 yılında Halfeti, 2015 yılında Şavşat, 2016 yılında ise Uzundere'nin ağa katılmasıyla birlikte Yavaş Şehir Türkiye Ağı'na üye olan şehir sayısı 11 olmuştur.

Tablo 1: Yavaş Şehir Türkiye Ağına Üye Olan Şehirler ve Üyelik Tarihleri

\begin{tabular}{|l|l|}
\hline Yavaş Şehir & Yavaş Şehir Üyelik Tarihi \\
\hline Seferihisar (İzmir) & 2009 \\
\hline Akyaka (Muğla) & 2011 \\
\hline Gökçeada (Çanakkale) & 2011 \\
\hline Taraklı (Sakarya) & 2011 \\
\hline Yenipazar (Aydın) & 2011 \\
\hline Yalvaç (Isparta) & 2012 \\
\hline Perşembe (Ordu) & 2012 \\
\hline Vize (Kırklareli) & 2012 \\
\hline Halfeti (Şanlıurfa) & 2013 \\
\hline Şavşat (Artvin) & 2015 \\
\hline Uzundere (Erzurum) & 2016 \\
\hline
\end{tabular}

Kaynak: Yavaş Şehir Türkiye ağına üye olan şehirlerin kurumsal internet sitelerinden derlenmiştir.

Çalışma çerçevesinde Yavaş Şehir Türkiye Ağı́na üye olan şehirlerin kurumsal internet siteleri içerik analizine tabi tutulmuştur. İçerik analizi sırasında şehirlerin internet sitelerinde yavaş şehir hareketine ilişkin vermiş oldukları bilgiler incelenmiştir. Elde edilen bulgulara Tablo 2'de yer verilmiştir. Üyelik kriterleri arasında da yer alan, ağa üye olan şehirlerin internet sitelerinde yavaş şehir hareketinin logosuna yer vermesi incelenen ilk konu olmuştur. Buna göre, ağa üye olan on bir şehirden altııının internet sitelerinin ana sayfalarında yavaş şehir logosuna yer verdikleri tespit edilmiştir. Bu şehirler arasında; Seferihisar, Yalvaç, Perşembe, Vize, Şavşat ve Uzundere yer almaktadır. Ancak bazı şehirlerin sitelerinde logo, belediye logosunun yanına konumlandırımamışır. Bu 


\section{Ömer Çoban ve Serhat Harman}

şehirlerin ağa üye olduğunu tespit edebilmek için ana sayfanın tümünü kontrol etmek gerekmektedir.

Tablo 2: Yavaş Şehir Türkiye Ağına Üye Olan Şehirlerin Kurumsal İnternet Sitelerine İlişkin Bulgular

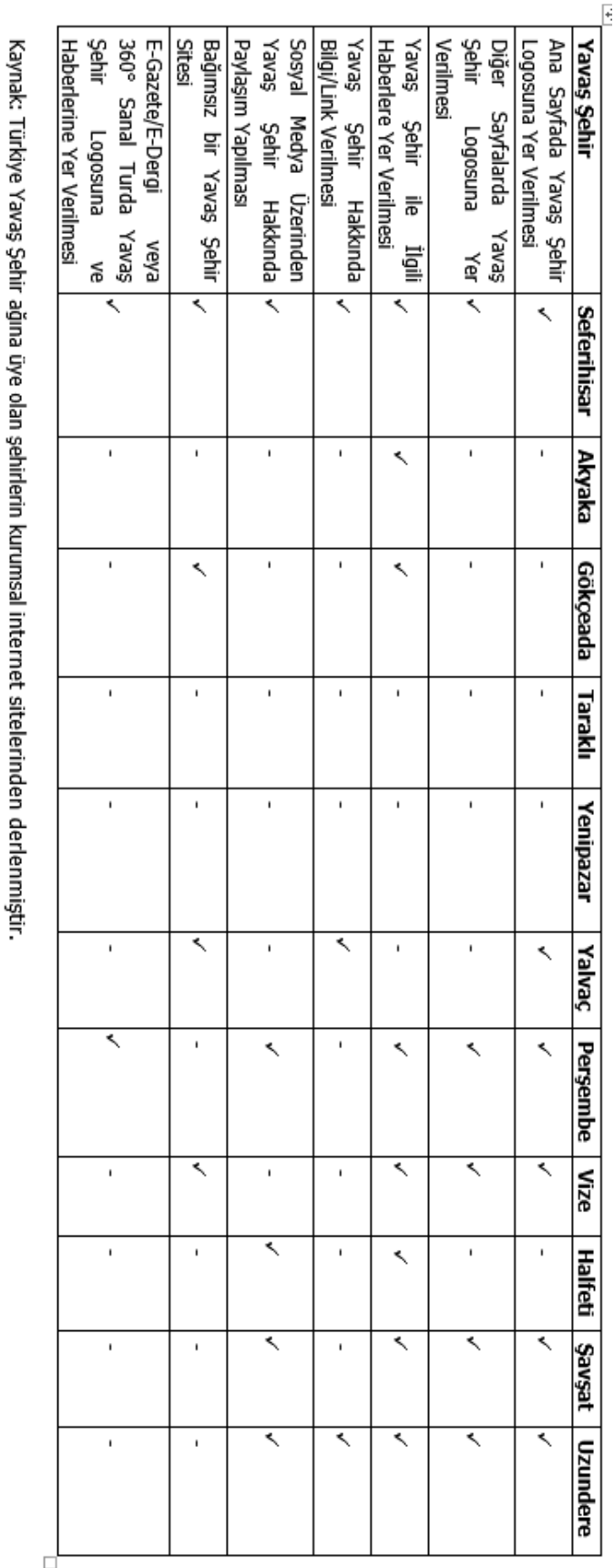

245 
Yavaş Şehir (Cittaslow) Türkiye Ağı'na Üye Olan Şehirlerin İnternet Sitelerinde Yavaş Şehir Temasının Görünürlüğü Üzerine Bir Araştırma

Araştırmada ikinci olarak incelenen konu, ana sayfa haricindeki sayfalarda yavaş şehir logosuna yer verilip vermediğidir. Seferihisar, Perşembe, Vize, Şavşat ve Uzundere ana sayfa dışındaki sayfalarda da yavaş şehir logosuna yer vermiştir. Bu şehirler yavaş şehir logosunu sayfa değişse bile görünecek bir bölüme yerleştirdikleri için tüm sayfalarda logo görünmektedir. Ana sayfada logoya yer veren Yalvaç ise logoyu sabit bir bölüme yerleştirmediği için diğer sayfalarda logo görünmemektedir.

Araştırma çerçevesinde ele alınan bir başka konu, şehir sitesinde yavaş şehir ile ilgili haberlere yer verilip verilmediğidir. Seferihisar, Akyaka, Gökçeada, Perşembe, Vize, Halfeti, Şavşat ve Uzundere yavaş şehir ile ilgili haberlere sitelerinin farklı bölümlerinde yer vermiştir. Bazı şehirlerin sitesinde sadece kendi şehirleriyle alakalı haberlere yer verilmekteyken bazı şehirlerde ise yavaş şehir ile ilgili genel haberler de duyurulmaktadır. Şehirlerin internet siteleri üzerinde yapılan bir başka inceleme ise yavaş şehir hakkında bilgi/link verilip verilmediğine bakılmasıdır. Buna göre üç şehir sitesinde yavaş şehir hakkında bilgi vermiştir. Bu şehirler Seferihisar, Yalvaç ve Uzundere şeklinde sıralanmaktadır. Ancak, bu şehirlerin birçoğunda bilgi paylaşımı site içerisinde değil, yavaş şehir logosu tıklandığında www.cittaslowturkiye.org yönlendirmesiyle yapılmaktadır.

Yavaş Şehir Türkiye Ağı'na üye olan beş şehir sosyal medya hesapları üzerinden yavaş şehir hakkında paylaşımlarda bulunmaktadır. Bu şehirler, Seferihisar, Perşembe, Halfeti, Şavşat ve Uzundere olarak tespit edilmiştir. Belediye sitelerinde genellikle iletişim bölümünde yer verilen sosyal medya sitelerine ait ikonlar tıklandığında, bazılarında belediyelerin kurumsal hesaplarına bazılarında ise belediye başkanlarının şahsi sosyal medya hesaplarına erişim gerçekleşmektedir. Bahsi geçen şehirlere ait hesaplarda yavaş şehir hakkında paylaşımlar yapıldığı tespit edilmiştir.

Araştırma çerçevesinde ağa üye şehirlerin internet sitelerinde kendilerine ait bağımsız bir yavaş şehir sitesinin linkine yer verilip verilmediğine bakılmıştır. Seferihisar, Gökçeada, Yalvaç ve Vize'nin kendilerine ait yavaş şehir sitesine link verdikleri tespit edilmiştir. Son olarak, ağa üye olan şehirlerin internet sitelerinde yer verdikleri e-gazete, e-dergi veya $360^{\circ}$ sanal turda yavaş şehir logosuna ve haberlerine yer verilip verilmediği incelenmiştir. Seferihisar çıkarmış olduğu e-gazetenin ana sayfasında yavaş şehir logosuna yer vermenin yanı sıra gazetenin içinde de yavaş şehir ile ilgili haberlere yer vermiştir. Perşembe'nin ise 


\section{Ömer Çoban ve Serhat Harman}

internet sayfasında yer vermiş olduğu $360^{\circ}$ sanal turda yavaş şehir logosuna yer verdiği tespit edilmiştir.

\section{SONUÇ VE ÖNERİLER}

Günümüzde yavaş şehir hareketi şehirlerin kendine özgü kültürel ve tarihsel kaynaklarının korunmasına katkı sağlarken, aynı zamanda yavaş şehir diğer şehirlere kıyasla farklılaştırılmasında ve ziyaretçiler tarafından tercih edilen yerler haline getirilmesinde önemli bir rol oynamaktadır. Bu nedenle yavaş şehir kriterlerini sağlama potansiyeli bulunan şehirlerin, yavaş şehir unvanı alabilmek için bir yarış içinde oldukları söylenebilir. Bu noktada yavaş şehir temasının görünürlüğü ve farkındalı̆ının arttırıması son derece önem arz etmektedir. Bu çalışmada da Yavaş Şehir Türkiye Ağı'na üye olan şehirlerin internet sitelerinde yavaş şehir temasının görünürlüğünü irdelemek üzere nitel bir araştırma yapılmıştır.

Araştırmadan elde edilen bulgulardan hareketle ağa üye olan şehirlerden Seferihisar'ın incelenen tüm alanlarda yavaş şehir hareketinin görünürlüğüne dikkat ettiği söylenebilir. Seferihisar'ın Yavaş Şehir Türkiye Ağı'nın kurucusu ve dolayısıyla ağın başkenti olması dolayısıyla yavaş şehir temasının görünürlüğü hususunu diğer şehirlerden daha ciddi bir şekilde ele aldığı sonucu ortaya çıkmaktadır. Vize, Yalvaç ve Gökçeada'nın, Seferihisar'dan sonra yavaş şehir ile ilgili görünürlüğe en fazla önem veren şehirler olduğu tespit edilmiştir. Bu şehirleri Yenipazar ve Halfeti izlemektedir. Diğer taraftan, Akyaka ve Taraklı'nın internet sitelerinde yavaş şehir hareketine dair hiçbir bilgiye yer verilmemiş olması ciddi bir eksiklik olarak göze çarpmaktadır. Çünkü hem Akyaka hem de Taraklı Seferihisar'dan hemen sonra birliğe dahil olan şehirler arasında yer almaktadır. Üyelik tarihi üzerinden dört sene geçmiş olmasına rağmen şehir sitelerinde bu şehirlerin yavaş şehir hareketine üye olduğuna dair en ufak bir bilgi bulunmamaktadır.

Küreselleşmiş günümüz dünyasında internet siteleri kurumların, paydaşlarıyla etkin bir iletişim yürütebilecekleri alanların başında gelmektedir. Bu durum, yavaş şehir Türkiye ağına üye olan şehirlerin ziyaretçilerine ve paydaşlarına ulaşmaları ve yavaş şehir ağının genişlemesi bakımından da geçerlidir. Dolayısıyla, Yavaş Şehir Türkiye Ağı'na üye olan şehirlerin internet sitelerinde yavaş şehir temasının görünürlügünün ve farkındalığının arttırılması konusunda dikkat etmesi gereken bazı noktalar bulunmaktadır. Bu noktalar; 
- Yavaş şehir logosuna şehrin kurumsal internet sitesinin ana sayfasında ve diğer tüm alt sayfalarında belediye logosuyla birlikte görünür bir alanda yer verilmelidir.

- Şehirlerin internet sitelerinde yavaş şehir ve yavaş yemek felsefesi tanıtılmalı ve yavaş şehir ile ilgili haberlere yer verilmelidir.

- Şehirlerin kurumsal sosyal medya hesapları bulunmalı ve bu hesaplardan yavaş şehir ile ilgili güncel olarak bilgi ve haber paylaşımı yapılmalıdır.

- Yavaş Şehir Türkiye Ağı'na üye olan şehirler kurumsal internet siteleri haricinde "www.cittaslow.org" uzantılı internet sitesini yayına sunmalı ve bu site üzerinden de iletişim çabalarına girmelidirler.

- Şehirler yavaş şehir ile ilgili düzenli olarak bültenler yayınlayabilir veyahut çıkarmış oldukları e-gazete veya e-dergilerde yavaş şehir logosuna ve yavaş şehir hareketi hakkında bilgi ve haberlere yer vermelidirler.

Yapılan içerik analizi sonucunda Yavaş Şehir Türkiye Ağı'na üye olan şehirlerin, yavaş şehir temasının görünürlüğü hususunda çok farklı uygulamaların bulunduğu anlaşılmaktadır. İlerleyen dönemlerde bu konuda çalışacak araştırmacılar uygulamalarda bu denli farklılığın bulunmasının nedenlerini araştırabilirler. Buna ek olarak, yurtdışında diğer yavaş şehirlerin internet siteleri üzerinden kurumsal iletişim stratejileri incelenerek Türkiye'deki yavaş şehirler ile karşılaştırmalar yapılabilir.

Yapılan çalışmanın birtakım sınırılıkları bulunmaktadır. Verilerin kısıtlı bir zaman diliminde internet siteleri üzerinden toplanmış olması ve kolayca niteliği değiştirilebilecek veriler olması nedeniyle farklı tarihlerde internet sitelerini ziyaret edenler tarafından farklı sonuçlarla karşılaşılması olasıdır. Bununla birlikte, yavaş şehirler üzerine yapılan çalışmaların belli alanlara sıkışmış olması ve az sayıda ampirik çalışma bulunması nedeniyle, alanyazında araştırma bulgularını tartışacak nitelikte çalışmaya rastlanmamıştır.

\section{KAYNAKÇA}

Bahtiyar Karadeniz, C. (2014). Sürdürülebilir Turizm Bağlamında Sakin Şehir Perşembe. Uluslararası Sosyal Araştırmalar Dergisi, 7(29), 84107.

Baldemir, E., Kaya, F. ve Şahin, T.K. (2013). A Management Strategy Within Sustainable City Context: Cittaslow. Procedia-Social and Behavioral Sciences, 99, 75-84. 


\section{Ömer Çoban ve Serhat Harman}

Baş, T. ve Akturan, U. (2008). Nitel Araştırma Yöntemleri: Nvivo 7.0 İle Nitel Veri Analizi. Ankara: Seçkin Yayıncılık.

Baykan, N.M. (2014). Farklı Ulaşım Seçeneklerinin Sakin Şehir (Cittaslow) Ölçütleri Kapsamında Değerlendirilmesi: Seferihisar-Sığacık Örneği (Yayımlanmamış Yüksek Lisans Tezi). Çukurova Üniversitesi Fen Bilimleri Enstitüsü, Adana.

Bilgin, N. (2006). Sosyal Bilimlerde İçerik Analizi: Teknikler ve Örnek Çalışmalar. Ankara: Siyasal Kitabevi.

Broadway, M. (2015). Implementing the Slow Life in Southwest Ireland: A Case Study of Clonakilty and Local Food. Geographical Review, 105(2), 216-234.

Chung, N. ve Koo, C. (2015). The Use of Social Media in Travel Information Search. Telematics and Informatics, 32, 215-229.

Cittaslow (2015). http://www.cittaslow.org/download/DocumentiUfficiali/ CITTASLOW_LIST_november2014.pdf (12.02.2015)

Cittaslow (2016). http://www.cittaslow.org (27.10.2016)

Cittaslow Polonya (2015). http://cittaslowpolska.pl/aktualnosciczytaj/297/olsztynek-wprowadza-pasym-i-gorowo-ilaweckie-do-cit taslow (20.02.2015)

Cittaslow Türkiye (2015a). http://cittaslowturkiye.org/?page_id=1063 (10.03.2015)

Cittaslow Türkiye (2015b). http://cittaslowturkiye.org/?page_id=1151 (01.03.2015)

Cittaslow Türkiye (2015c). http://cittaslowturkiye.org/?page_id=1549 (20.02.2015)

Cittaslow Türkiye (2016). http://cittaslowturkiye.org/?page_id=1549 (20.10.2016)

Cosar, Y. ve Kozak, M. (2014). Slow Tourism (Cittaslow) Influence over Visitors' Behavior. A.G. Woodside ve M. Kozak (Ed.), Tourists' Behaviors and Evaluations (Advances in Culture, Tourism and Hospitality Research, Volume 9 (ss. 21-29). Bingley: Emerald Group Publishing Limited.

Coşar, Y. (2013). Yavaş Şehir (Cittaslow) Olgusunun Turist Davranışları ve Yerel Halkın Kentsel Yaşam Kalitesi Algısına Etkileri (Yayımlanmamış Doktora Tezi). Dokuz Eylül Üniversitesi Sosyal Bilimler Enstitüsü, İzmir.

Çerçi, A. (2013). Destinasyon Markalama ve Yavaş Şehir Seferihisar'ın Destinasyon Marka İmajı (Yayımlanmamış Yüksek Lisans Tezi). Hacettepe Üniversitesi Sosyal Bilimler Enstitüsü, Ankara. 
Yavaş Şehir (Cittaslow) Türkiye Ağı'na Üye Olan Şehirlerin İnternet

Sitelerinde Yavaş Şehir Temasının Görünürlüğü Üzerine Bir Araştırma

Çoban, Ö. (2010). Paylaşım Olgusunda Meydana Gelen Değişiklikler Ve Günümüz Sosyal Ve İş Yaşamına İzdüşümler. Erciyes Üniversitesi Sosyal Bilimler Enstitüsü Dergisi, 28, 345-359.

Doğutürk, G. (2010). Mimari ve Yaşam Kalitesi Bağlamında Yavaş Şehir Hareketi ve Seferihisar Örneği (Yayımlanmamış Yüksek Lisans Tezi). Mimar Sinan Güzel Sanatlar Üniversitesi Fen Bilimleri Enstitüsü, İstanbul.

Ekincek, S. (2014). Sakin Şehir (Cittaslow) Yöneticilerinin Sakin Şehir Hareketine ve Sürdürülebilirliğe Yönelik Değerlendirmeleri (Yayımlanmamış Yüksek Lisans Tezi). Anadolu Üniversitesi Sosyal Bilimler Enstitüsü, Eskişehir.

Erten, S. (2009). Cittaslow Yavaş Şehir Seferihisar. Arredamento Mimarlık Dergisi, 227(9), 106-109.

Eşitti, B. ve Demir Harputluoğlu, D. (2015). Citta Slow Şehirlerde Yerel Halkın Earth Markete Yaklaşımı: Gökçeada Destinasyonu Örneği. Journal of Tourism and Gastronomy Studies, 3(1), 64-71.

Georgica, G. (2015). The Tourist's Perception about Slow Travel-A Romanian Perspective. Procedia Economics and Finance, 23, 15961601.

Göçkan, E. (2012). İzmir İli Yavaş Şehir Seferihisar Örneğinde Doğal ve Kültürel Yapı Üzerine Araştırmalar (Yayımlanmamış Yüksek Lisans Tezi). Ege Üniversitesi Fen Bilimleri Enstitüsü, İzmir.

Görkem, O. ve Öztürk, Y. (2014). Gastronomic Reflections of Cittaslow Movement on Local Cuisine: The Case Study of Seferihisar (İzmir, Turkey). International Scientific Journal Turizam, 18(1), 11-21.

Grzelak-Kostulska, E., Hołowiecka, B. ve Kwiatkowski, G. (2011). Cittaslow International Network: An Example of a Globalization Idea?. P. Mácha ve T. Drobík (Ed.), The Scale of Globalization Think Globally, Act Locally, Change Individually in the 21st Century (ss. 186-192). Ostrava: University of Ostrava Yayınları.

Günerhan, S.A., Erdem, Ü. ve Günerhan, H. (2010). Çevre ve Enerji Açısından Yavaş Şehir Hareketinin Gelişimi. Tesisat Mühendisliği, 118(4), 32-37.

Güven, E. (2011). Yavaş Güzeldir: Yavaş Yemekten Yavaş Medyaya Hızlı Tüketime Dair Bir Çözüm Önerisi. Selçuk İletişim Dergisi, 7(1), 113121.

Jacobsen, J.K.S. ve Munar, A.M. (2012). Tourist Information Search and Destination Choice in a Digital Age. Tourism Management Perspectives, 1, 39-47. 


\section{Ömer Çoban ve Serhat Harman}

Jarvis, H. (2015). Community-led Housing and 'Slow' Opposition to Corporate Development: Citizen Participation as Common Ground?. Geography Compass, 9(4), 202-213.

Jung, H.T., Ineson, M.E. ve Miller, A. (2014). The Slow Food Movement and Sustainable Tourism Development: A Case Study of Mold, Wales. International Journal of Culture, Tourism and Hospitality Research, 8(4), 432-445.

Karabag, O., Yucel, F. ve Inal, M.E. (2012). Cittaslow Movement: An Opportunity for Branding Small Towns and Economic Development in Turkey. International Journal of Economics and Research, 313, 64-75.

Karakurt Tosun, E. (2013). Yaşam Kalitesi Ekseninde Şekillenen Alternatif Bir Kentsel Yaşam Modeli: Yavaş Kentleşme Hareketi. Uludağ Üniversitesi İktisadi ve İdari Bilimler Fakültesi Dergisi, 32(1), 215237.

Keskin, E.B. (2010). Sürdürülebilir Kent Kavramına Farklı Bir Bakış Olarak Yavaş Şehirler (Cittaslow): Seferihisar Örneği (Yayımlanmamış Yüksek Lisans Tezi). Dumlupınar Üniversitesi Sosyal Bilimler Enstitüsü, Kütahya.

Keskin, E.B. (2012). Sürdürülebilir Kent Kavramına Farklı Bir Bakış: Yavaş Şehirler (Cittaslow). PARADOKS Ekonomi, Sosyoloji ve Politika Dergisi, 8(1), 81-99.

Mayer, H. ve Knox, P.L. (2006). Slow Cities: Sustainable Places in a Fast World. Journal of Urban Affairs, 28(4), 321-334.

Meng, B. ve Choi, K. (2016). The Role of Authenticity in Forming Slow Tourists' Intentions: Developing an Extended Model of GoalDirected Behavior. Tourism Management, 57, 397-410.

Miele, M. (2008). Cittaslow: Producing Slowness Against the Fast Life. Space and Polity, 12(1), 135-156.

Mutdoğan, S. (2010). Seferihisar Örneğinde Sakin Şehir Hareketi. Greenage Symposium. Mimar Sinan Güzel Sanatlar Üniversitesi Mimarlık Fakültesi, İstanbul, 6-8 Aralık 2010, 1-10.

Nilsson, J.H., Svärd, A.C., Widarsson, Å. ve Wirell, T. (2011). Cittaslow Eco-Gastronomic Heritage as a Tool for Destination Development. Current Issues in Tourism, 14(4), 373-386.

Onaran, D.C. (2013). Yavaş Şehirlerde Kentsel Kimlik (Yayımlanmamış Yüksek Lisans Tezi). Mimar Sinan Güzel Sanatlar Üniversitesi Fen Bilimleri Enstitüsü, İstanbul.

Özgenç, Ö. (2012). İdeal Toplum Düzeni Arayışında Kurgulanan Kentsel Planlamalar, Ütopyalar ve Yavaş Şehir Akımı (Yayımlanmamış 
Yavaş Şehir (Cittaslow) Türkiye Ağı'na Üye Olan Şehirlerin İnternet Sitelerinde Yavaş Şehir Temasının Görünürlüğü Üzerine Bir Araştırma

Yüksek Lisans Tezi). Mimar Sinan Güzel Sanatlar Üniversitesi Fen Bilimleri Enstitüsü, İstanbul.

Özkan, H.C. (2011). Bir Sürdürülebilir Kent Modeli: Yavaş Şehir Hareketi (Yayımlanmamış Yüksek Lisans Tezi). Yıldız Teknik Üniversitesi Fen Bilimleri Enstitüsü, İstanbul.

Öztürk, A. (2012a). Bir Yerleşim Birimi Olarak Kent Anlayışında Yeni Politika: Yükselen Değer Olarak "Yavaş Kent" (Cittaslow) (Yayımlanmamış Yüksek Lisans Tezi). Ege Üniversitesi Sosyal Bilimler Enstitüsü, İzmir.

Öztürk, S. (2012b). Small Towns Reshaping Their Urban Planning Policies Joining in the Cittaslow International Network: The Case of Seferihisar in Turkey (Yayımlanmamış Yüksek Lisans Tezi). Orta Doğu Teknik Üniversitesi Sosyal Bilimler Enstitüsü, Ankara.

Pecsek, B. (2016). Revitalizing Tourism in Small Regional Towns Through Folklore-Driven Slow Tourism: The Example of Matyó Land, Hungary. Dos Algarves: A Multidisciplinary e-Journal, 27, 94-119.

Polat, E. (2011). Ağır Ağır Çıkacaksın Bu Merdivenlerden: Yavaş Kent Hareketi (Cittaslow). Mimarlık Dergisi, 359(3).

Semmens, J. ve Freeman, C. (2012). The Value of Cittaslow as an Approach to Local Sustainable Development: A New Zealand Perspective. International Planning Studies, 17(4), 353-375.

Servon, L.J. ve Pink, S. (2015). Cittaslow: Going Glocal in Spain. Journal of Urban Affairs, 37(3), 327-340.

Sezgin, M. ve Ünüvar, Ş. (2011). Yavaş Şehir Sürdürülebilirlik ve Şehir Pazarlaması Ekseninde. Konya: Çizgi Kitabevi.

Sırım, V. (2012). Çevreyle Bütünleşmiş Bir Yerel Yönetim Örneği Olarak "Sakin Şehir" Hareketi ve Türkiye'nin Potansiyeli. Tarih Kültür ve Sanat Araştırmaları Dergisi, 1(4), 119-131.

Steele, W. (2012). Do We Need a 'Slow Housing' Movement?. Housing, Theory and Society, 29(2), 172-189.

Sünnetçioğlu, S., Can, A. ve Durlu-Özkaya, F. (2012). Yavaş Turizmde Coğrafi İşaretlemenin Önemi, 13. Ulusal Turizm Kongresi, 6-9 Aralık 2012, Antalya, 953-962.

Şahin, İ. ve Kutlu, S.Z. (2014). Cittaslow: Sürdürülebilir Kalkınma Ekseninde Bir Değerlendirme. Journal of Tourism and Gastronomy Studies, 2(1), 55-63.

Toplu, H.İ. (2012). Yavaş Şehirler (Cittaslow/SlowCities) ve Halk Sağlığı (Yayımlanmamış Yüksek Lisans Tezi). Ege Üniversitesi Fen Bilimleri Enstitüsü, İzmir. 


\section{Ömer Çoban ve Serhat Harman}

Yalçın, A. ve Yalçın S. (2013). Sürdürülebilir Yerel Kalkınma İçin Cittaslow Hareketi Bir Model Olabilir Mi?. Sosyal ve Beşeri Bilimler Dergisi, $5(1), 32-41$.

Yıldırım, A. ve Şimşek, H. (2008). Sosyal Bilimlerde Nitel Araştırma Yöntemleri. Ankara: Seçkin Yayıncılık.

Yurtseven, H.R. ve Kaya, O. (2011). Slow Tourists: A Comparative Research Based on Cittaslow Principles. American International Journal of Contemporary Research, 1(2), 91-98.

Yurtseven, R., Kaya, O. ve Harman, S. (2010). Yavaş Hareketi. Ankara: Detay Yayıncllı. 